\title{
Composting the solid fraction of separated pig manure with sawdust, chopped straw or shredded green waste
}

T. Cota Nolan, S.M. Troy, P.B. Lynch, P.G. Lawlor

${ }^{1}$ Teagasc, Moorepark, Fermoy, Co.Cork, Ireland

${ }^{2}$ NUI Galway, Galway, Ireland

Email:tereza.nolan@teagasc.ie

Introduction Since August 2006, with the implementation of Statutory Instrument No. 378 (S.I. No. 378) the potential for application of organic fertiliser to land in Ireland has been greatly limited. Therefore, alternative management strategies for pig manure, such as composting, should be considered and explored. Composting can increase the fertilizer value of animal manure by binding the mineral nutrients into a stable organic structure. The objective of this study was to investigate the co-mixing and composting of the separated solid fraction of pig manure with sawdust, shredded green waste (a mixture of tree leaves, foliage and small twigs) or chopped straw and to determine the suitability of the resulting product as a compost. The hypothesis is that the addition of bulking agents to the manure will improve the compost process.

Material and methods A decanter centrifuge (GEA Westfallia Separator UCD 205, GEA WestfaliaSurge GmbH, Germany) was used to perform the mechanical separation of the liquid pig manure. Average dry matter (DM) of liquid pig manure before separation was $24 \mathrm{~g} / \mathrm{kg}(\mathrm{SD}=0.17)$. The $\mathrm{DM}$ of the solid and liquid fraction after separation was $380 \mathrm{~g} / \mathrm{kg}$ $(\mathrm{SD}=3.19)$ and $3 \mathrm{~g} / \mathrm{kg}(\mathrm{SD}=0.07)$, respectively. The manure to bulking agent ratio was $c .2: 1$ (by volume). There were 4 treatments each with 4 replicates: (T1) $38 \mathrm{~kg}$ of solid fraction of separated pig manure (SPM); (T2) $38 \mathrm{~kg}$ of SPM $+9.5 \mathrm{~kg}$ of sawdust; (T3) $38 \mathrm{~kg}$ of SPM $+9.5 \mathrm{~kg}$ of shredded green waste and (T4) $38 \mathrm{~kg}$ of SRM $+2.8 \mathrm{~kg}$ of chopped straw. Sixteen fully insulated compost tumblers (Jora JK270 Composter, Joraform AB, Sweden) were used to compost the mixtures. A replicate of each treatment was initiated each day for 4 days. Compost temperature was recorded daily with a long stemmed thermometer. Aeration was provided by turning the tumblers daily. The experiment lasted for 56 days and samples were collected from each tumbler on days $0,3,7,14,21,28,42$ and 56 for $\mathrm{DM}$ and $\mathrm{pH}$ analyses

Results The temperature curves for all 4 treatments were typical of those found in other pig manure composting studies (Huang et al., 2006, Szanto et al., 2007), with three distinct phases observed. In the first initial mesophilic phase the temperature inside the compost piles began to rise immediately after piling, rapidly achieving the peak temperature. Initial temperature (Day 0) was 32.4, 34.8, 31.9 and $32.0^{\circ} \mathrm{C}$ for T1, T2, T3 and T4, respectively. By Day 2-3 temperatures had reached $>60^{\circ} \mathrm{C}$ for all treatments. Maximum temperature for $\mathrm{T} 1\left(66.5^{\circ} \mathrm{C}\right)$, T2 $\left(66.8^{\circ} \mathrm{C}\right), \mathrm{T} 3\left(67.1^{\circ} \mathrm{C}\right)$ and $\mathrm{T} 4\left(64.3^{\circ} \mathrm{C}\right)$ were achieved on days 4, 2, 4 and 7, respectively. During the second phase, temperatures remained above $50^{\circ} \mathrm{C}$ for a period of $c$. 2 weeks in all 4 treatments. The final compost phase was characterized by a drop in temperature reaching ambient levels after c. 22 days for T3 and T4 and after 18 and 20 days for T1 and T2, respectively. The moisture content of a compost pile is generally recommended to be between 50 and $60 \%$. At Day 0 , moisture content of the compost piles were $64.1,51.7$, 61.0 and $58.2 \%$ for T1, T2, T3 and T4, respectively. From Day 3 onwards moisture content for T2, T3 and T4 remained below $60 \%$ and above $49 \%$. The change in $\mathrm{pH}$ for the 4 treatments showed a similar pattern. Initial pH (Day 0$)$ was 8.3 , 8.2, 8.1 and 8.5 for T1, T2, T3 and T4, respectively. The $\mathrm{pH}$ for T1, T2, T3 and T4 increased slightly on Day 3 to 8.7, 8.5, 8.5 and 8.7, respectively; and it was still slightly higher then initial pH on Day 7 being 8.5, 8.8, 8.5 and 8.7 for T1, T2, T3 and T4, respectively. From Day 14 onwards pH started to decrease and from Day 21 it did not vary much until the end of the experimental period on Day 56 when $\mathrm{pH}$ was 7.1, 7.1, 7.0 and 7.4 for T1, T2, T3 and T4, respectively. One explanation for the increase in $\mathrm{pH}$ between Day 0 and 7 may be the production of ammonia $\left(\mathrm{NH}_{3}\right)$ during ammonification and mineralization of organic Nitrogen as a result of high microbiological activity during this period.

Conclusions The pattern of temperature, moisture and $\mathrm{pH}$ showed that the separated solid fraction of pig manure was successfully composted with or without the addition of bulking agents (sawdust, shredded green waste or chopped straw). Currently a germination test and a respiration test using the compost samples are being performed to determine compost maturity and their suitability as growth media.

Acknowledgements This research was funded by the Irish Department of Agriculture and Food's Research Stimulus Fund Programme (RSFP) under the National Development Plan 2007-2013.

\section{References}

Huang, G.F., Wu, Q.T., Wong, J.W.C., Nagar, B.B. 2006. Bioresource Technology. 97, 1834-1842.

Szanto, G.L., Hamelers, H.M., Rulkens, W.H., Veeken, A.H.M. 2007. Bioresource Technology. 98, 2659-2670. 